[Chem. Pharm. Bull.

32( 3 ) $839-845$ (1984) $]$

\title{
Electrochemical Oxidation of Chlorpromazine-Cyclodextrin Inclusion Complex
}

\author{
Kiyoko Takamura, ${ }^{*}, a$ Satoshi InOUE, ${ }^{a}$ Fumiyo Kusu, ${ }^{a}$ \\ MASAKI OTAGIRI ${ }^{b}$ and KANETO UEKAMA ${ }^{b}$ \\ Tokyo College of Pharmacy, ${ }^{a}$ Horinouchi 1432-1, Hachioji, Tokyo 192-03, Japan, \\ and Faculty of Pharmaceutical Science, Kumamoto University, ${ }^{b}$ \\ Oe-honmachi 5-1, Kumamoto 862, Japan
}

(Received July 4, 1983)

\begin{abstract}
The electrochemical oxidation of a chlorpromazine (CPZ)-cyclodextrin (CyD) inclusion complex was studied in phosphate buffers by means of cyclic voltammetry.

The voltammogram of the CPZ-CyD system exhibits three oxidation waves. The first wave, which is due to the oxidation of $\mathrm{CPZ}$ to form its cation radical, is catalytic in nature, and its peak current depends on $\mathrm{pH}$ and on the buffer concentration. The second wave is attributed to the oxidation of CPZ cation radical-phosphate adduct. The third wave appears to be the result of further oxidation of $\mathrm{CPZ}$ sulfoxide-CyD complex.

The formation of an inclusion complex of CPZ with CyD leads to a lowering of the peak current of the first wave and a shift in the peak potential to the positive side at the same time. The presence of $\mathrm{CyD}$ exerts no appreciable effect on the second wave, suggesting a minor interaction between the radical and $\mathrm{CyD}$, and this is consistent with the absorption, circular dichroism, and ${ }^{1} \mathrm{H}$-nuclear magnetic resonance (NMR) spectra.

Based on these results, an electrochemical reaction mechanism for $\mathrm{CPZ}-\mathrm{CyD}$ system is proposed.
\end{abstract}

Keywords_-chlorpromazine-cyclodextrin inclusion complex; electrochemical oxidation; electrode reaction; glassy carbon electrode; voltammetry

Phenothiazine-based major tranquilizers such as chlorpromazine (CPZ) are very widely used as antipsychotic drugs, and much attention has been directed to their undesirable side effects, such as drug-induced hemolysis. ${ }^{1)}$ To avoid such effects as well as to protect the drugs from photodecomposition, combination with various components has been investigated. ${ }^{1,2)}$

Recently, cyclodextrins (CyDs), cyclic- $\alpha-1,4-\mathrm{D}$-glucose oligomers which form host-guest inclusion complexes with $\mathrm{CPZ}$, have been found promising for alleviating the adverse side effects of CPZ. ${ }^{1)}$ Fortunately, CyDs do not lessen the therapeutic effects of CPZ on the central nervous system of the rat and are not toxic to the human body. ${ }^{3,4)}$ However, a detailed explanation has not yet been presented for the effectiveness of CyDs in alleviating the defects of CPZ.

Chlorpromazine is easily oxidized electrochemically, ${ }^{5,6)}$ photochemically, ${ }^{7)}$ and enzymatically ${ }^{8)}$ to form $\mathrm{CPZ}$ sulfoxide $(\mathrm{CPZO})$ via the $\mathrm{CPZ}$ cation radical $\left(\mathrm{CPZ}{ }^{+}\right)$. It has often been pointed out that phenothiazine cation radicals may be active pharmacological entities $^{8-12)}$ and their oxidation potentials are correlated to clinical activity. ${ }^{13)}$ Thus, we considered it worthwhile to observe the oxidation potentials of $\mathrm{CPZ}$ and its cation radical in the presence of CyDs. If the electrode surface is regarded as a simple model of the receptor surface, the electrode reaction mechanism of CPZ-CyD systems may be suggestive of the interaction of $\mathrm{CPZ}$ with $\mathrm{CyDs}$ at the receptor site.

In this paper, an attempt has been made to elucidate the roles of CyDs in the overall electrochemical oxidation processes of CPZ. 
<smiles>CN(C)CCN1c2ccccc2Sc2ccc(Cl)cc21</smiles>

$\mathrm{CPZ}$<smiles>CN(C)CCCN1c2ccccc2Sc2ccc(Cl)cc21</smiles>

$\mathrm{CPZ} \cdot{ }^{+}$<smiles>CN(C)CCN1c2ccccc2S(=O)c2ccc(Cl)cc21</smiles>

CPZO

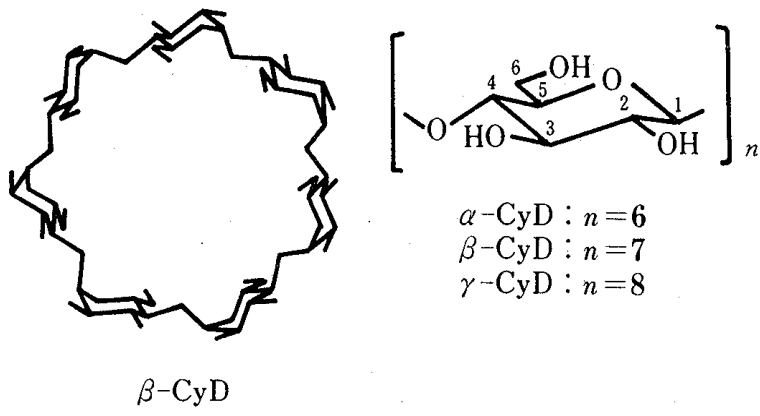

Chart 1

\section{Experimental}

Apparatus-Cyclic voltammetry and controlled potential electrolysis were carried out using an HA-101 potentiostat (Hokuto Denko, Ltd.) and an HA-107A function generator (Hokuto Denko, Ltd.). A glassy carbon rod polished with alumina powder $(0.3 \mu \mathrm{m})$ was used as a working electrode. Before each measurement, the electrolytic solution was deaerated with purified nitrogen gas. During measurement, the solutions were shielded from light and air, and the temperature was kept at $25 \pm 1^{\circ} \mathrm{C}$.

Absorption and circular dichroism (CD) spectra were recorded on a Hitachi model 200-10 spectrometer and a JASCO J-500C spectropolarimeter, respectively. Proton nuclear magnetic resonance $\left({ }^{1} \mathrm{H}-\mathrm{NMR}\right)$ spectra were obtained on a JEOL PS-100 machine.

Electroconductivity was measured with a model CM-2A instrument (Toa Electronics, Ltd.). The measurement was carried out in freshly distilled water at $25 \pm 0.1^{\circ} \mathrm{C}$.

Chemicals-Hydrochlorides of CPZ and CPZO were kindly provided by Shionogi Co., Ltd. and were used without further purification. The perchlorate salt of $\mathrm{CPZ}{ }^{+}{ }^{+}$was synthesized electrochemically according to the method of McCreery et al. ${ }^{14)} \alpha-, \beta$ - and $\gamma$-Cyclodextrins were kindly provided by Nippon Shokuhin Kako Co., Ltd., and were recrystallized from water. Maltopentaose was obtained from Wako Pure Chemical Industries Ltd. Phosphate buffer was used as base electrolyte solution, and the ionic strength was adjusted to 0.2 using $\mathrm{NaCl}$. In order to prevent its decomposition, $\mathrm{CPZ} .^{+}$was dissolved in $3 \mathrm{~N} \mathrm{HCl}$ for measurement of $\mathrm{CD}$ and absorption spectra and in $3 \mathrm{~N} \mathrm{DCl}$ for the ${ }^{1} \mathrm{H}-\mathrm{NMR}$ analysis. Under these conditions, CyDs and $\mathrm{CPZ}$ underwent almost no decomposition during measurement.

\section{Results and Discussion}

As shown in Fig. 1, the cyclic voltammogram of $\mathrm{CPZ}$ without CyD has three oxidation waves at $+0.65 \mathrm{~V},+0.90 \mathrm{~V}$ and $+1.10 \mathrm{~V}$ vs. a saturated calomel electrode (SCE). These waves correspond to the oxidation of $\mathrm{CPZ}$, that of $\mathrm{CPZ} \cdot{ }^{+}$-supporting electrolyte adduct and that of CPZO, respectively. ${ }^{15)}$ When $\alpha-, \beta$ - or $\gamma$-CyD was added to the CPZ solution, the peak current of the first oxidation wave $\left(i_{\mathrm{p} 1}\right)$ decreased and the peak potential $\left(E_{\mathrm{p} 1}\right)$ shifted to the positive side in the order of $\beta->\gamma->\alpha-\mathrm{CyD}$ (Fig. 1, dotted lines A-C). This order is the same as that of the stability constants of the CPZ-CyD complexes. ${ }^{16,17)}$ In contrast to CyD, maltopentaose, adopted as a linear-structured analogue of $\mathrm{CyD}$ having no tendency to form an inclusion complex, hardly affects the voltammogram of CPZ (Fig. 1, curve D). This indicates that the formation of $\mathrm{CPZ}-\mathrm{CyD}$ complexes results in both a shift of $E_{\mathrm{p} 1}$ and a decrease in $i_{\mathrm{p} 1}$.

To examine the electrochemical reaction of $\mathrm{CPZ}$ with $\mathrm{CyD}$, a controlled potential 


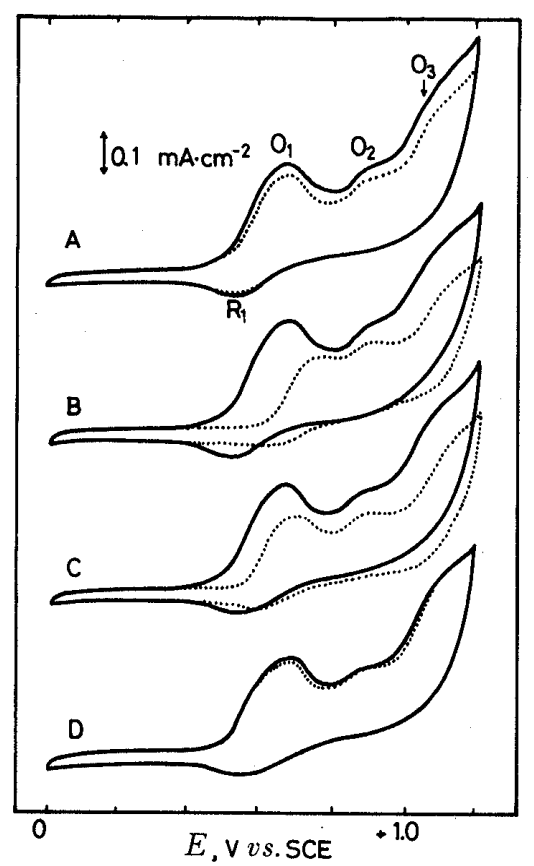

Fig. 1. Cyclic Voltammograms of $1.0 \times 10^{-3} \mathrm{M}$ $\mathrm{CPZ}$ with (----) and without $(-\mathrm{CyD}$ in 0.1 M Phosphate Buffer

Concentration of CyD: $1.0 \times 10^{-2} \mathrm{M} \alpha$-CyD (A) $1.0 \times 10^{-2} \mathrm{M} \beta$-CyD (B); $1.0 \times 10^{-2} \mathrm{M} \gamma-\mathrm{CyD}(\mathrm{C})$; $1.0 \times 10^{-2} \mathrm{M}$ maltopentaose (D). $\mathrm{pH}=3$.

electrolysis was carried out and the oxidation products were detected by absorption spectroscopy and thin-layer chromatography (TLC). ${ }^{15)}$ The final product of CPZ for each CyD used at the potential of either $E_{\mathrm{p} 1}$ or $E_{\mathrm{p} 2}$ was found to be CPZO-CyD by a comparison of the ultraviolet (UV) spectra and $R f$ values on TLC with those of pure CPZO-CyD mixture. During electrolysis, the solutions had a red tinge owing to a colored product identified as $\mathrm{CPZ}^{+{ }^{+}}$on the basis of a comparison of its absorption spectrum with that of synthetic CPZ ${ }^{+}{ }^{+}$. From these results, it may be said that the electrochemical oxidation of CPZ in the presence of CyDs takes place by essentially the same pathway as that for CPZ alone. ${ }^{15)}$

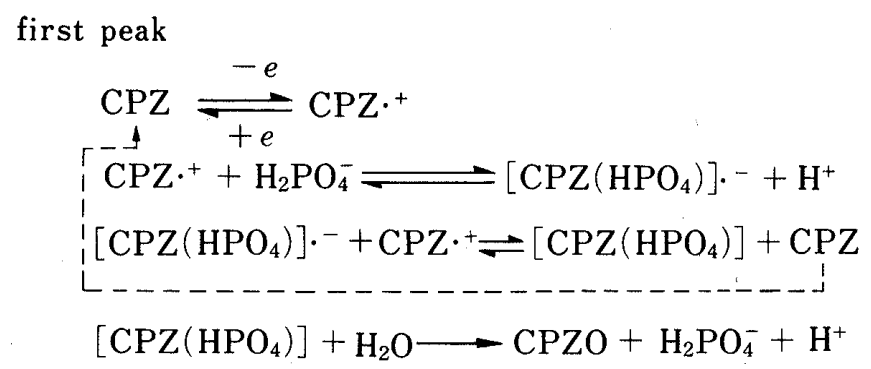

Chart 2

In the following discussion, $\beta$-CyD is preferred to other CyDs, unless otherwise noted, because of its ability to form the most stable complex with CPZ. In our previous paper, we proposed the following electrochemical oxidation mechanism for the first wave of CPZ. ${ }^{15}$ ) The cation radical $\mathrm{CPZ}^{+}$produced through a one-electron oxidation of $\mathrm{CPZ}$ reacts with a phosphate anion, one of the supporting electrolyte components, to form the $\mathrm{CPZ} \cdot{ }^{+}$-phosphate adduct. The adduct is then further oxidized by a neighboring $\mathrm{CPZ}^{+}$molecule through a disproportionation step.

The first oxidation peak current $i_{\mathrm{p} 1}$ may be represented by Eq. 5. ${ }^{18)}$

$$
i_{\mathrm{p} 1}=n F A C_{0}^{*} \sqrt{D k_{\mathrm{f}}}
$$

where $D$ is the diffusion coefficient, $C_{0}^{*}$, the bulk concentration of $\mathrm{CPZ}, A$, the area of the 
electrode, $F$, the Faraday constant, $n$, the number of electrons, and $k_{\mathrm{f}}$, the rate constant of the degradation of $\mathrm{CPZ}^{+}$in the bulk solution given by Eq. $6 .{ }^{13)}$

$$
k_{\mathrm{f}}=k^{\prime}\left[\mathrm{H}_{2} \mathrm{PO}_{4}^{-}\right] /\left[\mathrm{H}^{+}\right]
$$

On the basis of Eq. 5 and 6 , linear relations should be obtainable for both $i_{\mathrm{p} 1} v s$. $\left[\mathrm{H}_{2} \mathrm{PO}_{4}^{-}\right]^{1 / 2}$ and $\log i_{\mathrm{p} 1}$ vs. $\mathrm{pH}$. This was actually found to be the case in the previous investigation. ${ }^{15}$

In the presence of $\beta-\mathrm{CyD}$, similar relations were also obtained for the first peak height (Fig. 2), indicating that a similar reaction scheme holds for the first oxidation wave of the CPZ- $\beta$-CyD system.

As mentioned above, the addition of $\beta$-CyD to the CPZ solution leads to a decrease in $i_{\mathrm{p} 1}$. The reason for this should be the lower diffusion coefficient of the resulting CPZ- $\beta-\mathrm{CyD}$ complex. The diffusion coefficient and Stokes' diameter of CPZ- $\beta$-CyD were estimated by CPZ electroconductivity measurement with and without $\beta$-CyD. The straight lines in Fig. 3, in which the equivalent conductivity was plotted vs. square root of the concentration of $\mathrm{CPZ}$, show that $\mathrm{CPZH}^{+} \mathrm{Cl}^{-}$is completely dissociated even in the presence of $\beta$-CyD. The peak current $i_{\mathrm{p} 1}$ is directly proportional to the square root of the diffusion coefficient $D$, and $D$ is

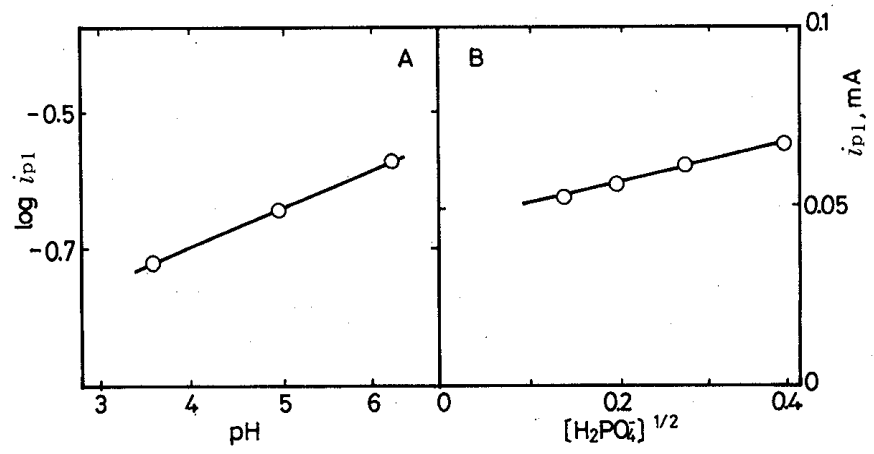

Fig. 2. A. Logarithm of Peak Current $i_{\mathrm{p} 1}$ vs. $\mathrm{pH}$ of Solution B. Peak Current $i_{\mathrm{p} 1}$ vs. Square Root of Buffer Concentration $[\mathrm{CPZ}]=1.0 \times 10^{-3} \mathrm{M} ;[\beta-\mathrm{CyD}]=1.0 \times 10^{-2} \mathrm{M}$.

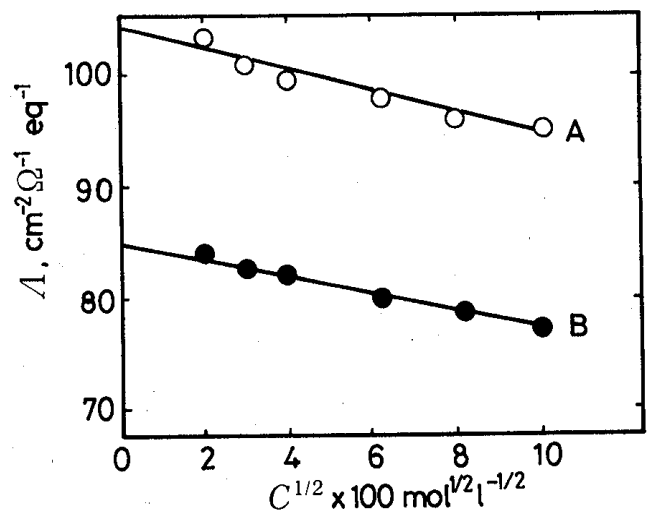

Fig. 3. Electroconductivity of $\mathrm{CPZ}$ with (B) and without (A) $\beta$-CyD in Distilled Water at $25^{\circ} \mathrm{C}$

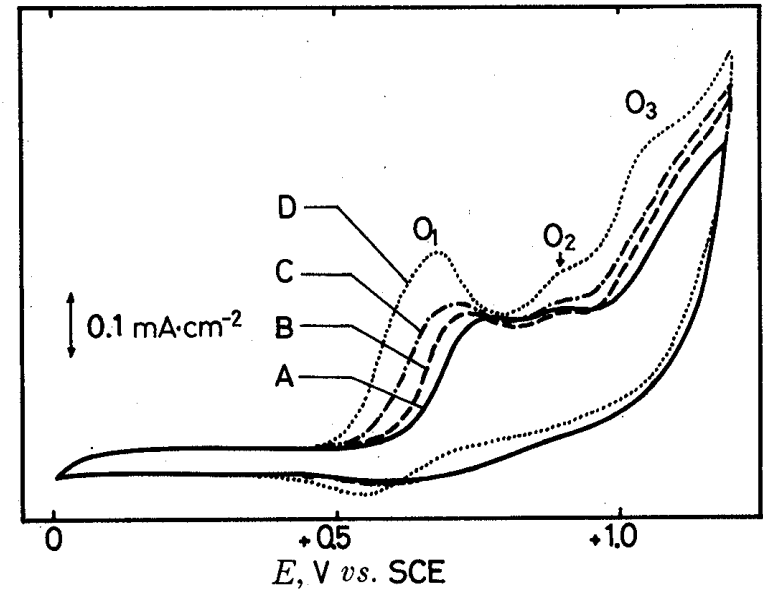

Fig. 4. Cyclic Voltammogram of $1.0 \times 10^{-3} \mathrm{M}$ $\mathrm{CPZ}$ with $(\mathrm{A}-\mathrm{C})$ and without (D) $\mathrm{CyD}$ in $0.1 \mathrm{M}$ Phosphate Buffer, $\mathrm{pH}=3.8$

Concentration of CyD: $1.0 \times 10^{-2} \mathrm{M} \beta$-CyD (A); $5.0 \times 10^{-2} \mathrm{M} \gamma-\mathrm{CyD}(\mathrm{B}) ; 5.0 \times 10^{-2} \mathrm{M} \alpha-\mathrm{CyD}(\mathrm{C})$. 
proportional to the equivalent conductivity at infinite dilution $\Lambda_{0}$. That $\Lambda_{0}$ of $\mathrm{CPZH}^{+} \mathrm{Cl}^{-}-\beta$ $\mathrm{CyD}$ is lower than that of $\mathrm{CPZH}^{+} \mathrm{Cl}^{-}$is obvious from Fig. 3, and thus it is apparent that the lowering of $D$ results in a decrease in $i_{\mathrm{p} 1}$.

The Stokes' diameters of $\mathrm{CPZH}^{+}$and the $\mathrm{CPZH}^{+}-\beta-\mathrm{CyD}$ complex were calculated according to Nakagaki and Okada. ${ }^{19)}$ The diameters $r$ were obtained from the following Eq. 7.

$$
r=0.82 \cdot|Z| /\left(\left(\Lambda_{\mathrm{CPZH}^{+}}^{0}-\lambda_{\mathrm{Cl}^{-}}^{0}\right) \eta^{0}\right)\left(\gamma_{\mathrm{C}} / \gamma_{\mathrm{S}}\right)
$$

In this equation, $|Z|$ signifies the charge number, $\gamma_{\mathrm{C}} / \gamma_{\mathrm{S}}$ the correction factor, $\eta^{0}$ the viscosity of the solvent, $\Lambda_{\mathrm{CPZH}^{+}}^{0}$ the equivalent conductivity at infinite dilution of $\mathrm{CPZH}^{+}$, and $\lambda_{\mathrm{Cl}}^{0}$ - the equivalent conductivity of $\mathrm{Cl}^{-}$. The charge of $\mathrm{CPZ}$ and viscosity of the solution were unchanged irrespective of the presence of $\beta$-CyD. The obtained size of $\mathrm{CPZH}^{+}$and that of its $\beta$-CyD complex were about 5 and $14 \AA$, respectively. These values seem reasonable, taking into account the sizes of molecular models of CPZ and CPZ- $\beta$-CyD. Thus, enlargement of the molecular size of the diffusing entity is responsible for the lowering of $D$.

The cyclic voltammograms of CPZ with $\alpha-\beta$ - or $\gamma$-CyD were obtained by keeping the complex concentrations constant at $9 \times 10^{-4} \mathrm{M}$, and the results are shown in Fig. 4 . In contrast with the first oxidation wave, the peak potential of the second wave $E_{\mathrm{p} 2}$ was not affected by
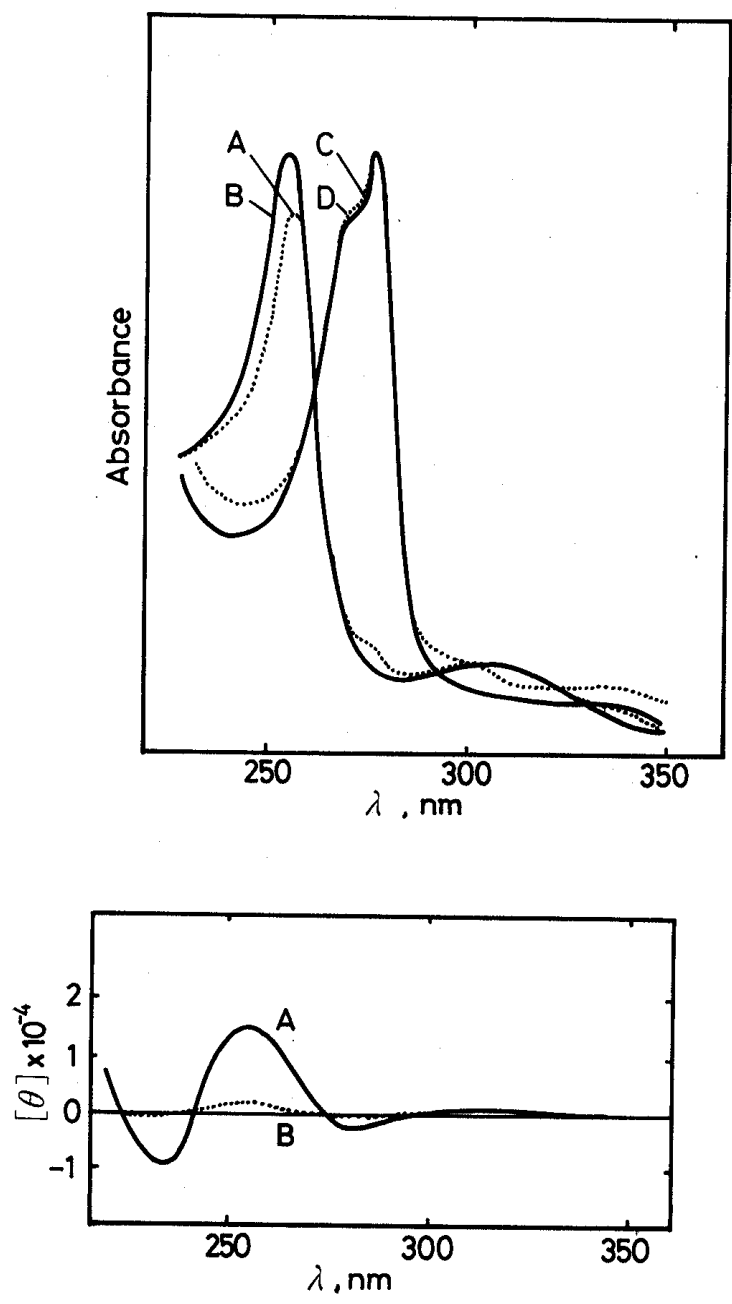

Fig. 6. CD Spectra of $2.5 \times 10^{-5} \mathrm{M} \mathrm{CPZ}$ with $5.0 \times 10^{-4} \mathrm{M} \beta-\mathrm{CyD}(\mathrm{A}), 2.3 \times 10^{-5} \mathrm{M} \mathrm{CPZ}{ }^{+}$ with $5.0 \times 10^{-4} \mathrm{M} \beta-\mathrm{CyD}(\mathrm{B})$ in $3 \mathrm{~N} \mathrm{HCl}$
Fig. 5. Absorption Spectra of $1.9 \times 10^{-5} \mathrm{M} \mathrm{CPZ}$ with (A) and without (B) $1.0 \times 10^{-3} \mathrm{M} \beta$-CyD and $1.5 \times 10^{-5} \mathrm{M} \mathrm{CPZ}^{+}$with (C) and without (D) $1.0 \times 10^{-3} \mathrm{M} \beta-\mathrm{CyD}$ in $3 \mathrm{~N} \mathrm{HCl}$

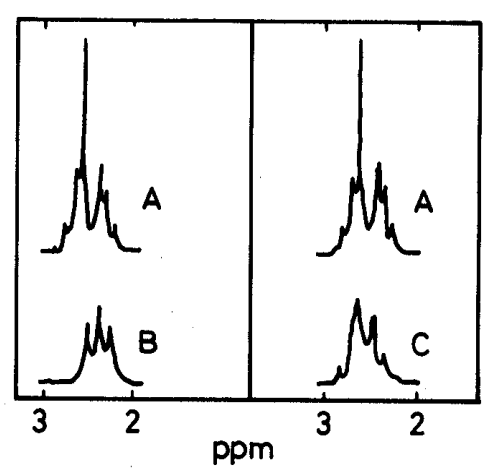

Fig. 7. ${ }^{1} \mathrm{H}-\mathrm{NMR}$ Spectra of $\beta$-CyD in $3 \mathrm{~N} \mathrm{DCl}$ Components: $1.0 \times 10^{-2} \mathrm{M} \beta$-CyD (A); $5.0 \times 10^{-3} \mathrm{M}$ $\beta$-CyD with $5.8 \times 10^{-3} \mathrm{M} \mathrm{CPZ} \mathrm{(B);} 5.0 \times 10^{-3} \mathrm{M} \beta$ $\mathrm{CyD}$ with $5.8 \times 10^{-3} \mathrm{M} \mathrm{CPZ}^{+}$(C). 
the existence of $\mathrm{CyD}$. The fact that $\alpha-, \beta$ - and $\gamma-\mathrm{CyD}$ had no effect on the oxidation potential of $\mathrm{CPZ} \cdot{ }^{+}$may suggest that no complexation of $\mathrm{CPZ} \cdot{ }^{+}$with $\mathrm{CyDs}$ took place.

To determine whether $\beta$-CyD can form a complex with $\mathrm{CPZ} \cdot{ }^{+}$or not, absorption, $\mathrm{CD}$ and ${ }^{1} \mathrm{H}-\mathrm{NMR}$ spectra of $\mathrm{CPZ} \cdot{ }^{+}$with $\beta$-CyD were examined. In Fig. 5, which shows the UV absorption spectra of $\mathrm{CPZ}$ and $\mathrm{CPZ}{ }^{+}{ }^{+}$with $\beta$ - $\mathrm{CyD}$, the absorptivity of $\mathrm{CPZ}$ with $\beta$-CyD differs from that of $\mathrm{CPZ}$ alone. On the other hand, the presence of $\beta$-CyD causes no appreciable change in absorption of $\mathrm{CPZ} \cdot{ }^{+}$. No $\mathrm{CD}$ band was observed for any solution of $\mathrm{CPZ}, \mathrm{CPZ} \cdot{ }^{+}$or $\beta-\mathrm{CyD}$, but the $\mathrm{CPZ}-\beta$-CyD mixture showed marked induced $\mathrm{CD}$ bands (Fig. 6, curve A) arising from the inclusion complex formed. ${ }^{16)}$ In contrast, the $\mathrm{CPZ} \cdot{ }^{+}-\beta$ CyD system hardly showed any induced $C D$ band, giving only a small band (curve B) derived from $\mathrm{CPZ}$ reproduced through reaction (3). These findings indicate that $\beta-\mathrm{CyD}$ is not capable of forming an inclusion complex with $\mathrm{CPZ} \cdot{ }^{+}$.

In the ${ }^{1} \mathrm{H}-\mathrm{NMR}$ spectra of $\mathrm{CPZ}$ with $\beta$-CyD, as shown in Fig. 7 , the peaks of $\beta$-CyD are shifted upfield by the anisotropic shielding of CPZ included in the cavity of $\beta$-CyD (curve B) ${ }^{16)}$ In the case of $\mathrm{CPZ} \cdot{ }^{+}-\beta$-CyD, only a broadening of the peaks was observed (curve $\mathrm{C}$ ), implying that the aromatic portion of $\mathrm{CPZ}{ }^{+}{ }^{+}$was not in the cavity of $\beta$-CyD.

The weak affinity of $\beta$-CyD for $\mathrm{CPZ} \cdot{ }^{+}$seems likely to be due to the polarity of the phenothiazine ring of $\mathrm{CPZ} \cdot{ }^{+}$. Recently, the relationship between the partition coefficients and stability constants of $\beta$-CyD-phenothiazine derivative complexes was discussed by Otagiri et $a l^{16)}$ It is considered that hydrophilic derivatives having low partition coefficients cannot form stable complexes, because of the hydrophobic property of the $\beta$-CyD cavity. Thus, a mutual attraction cannot be expected between hydrophilic $\mathrm{CPZ}^{\cdot{ }^{+}}$and the hydrophobic $\beta$-CyD cavity. Therefore, it may be reasonable to assume that a dissociation of $\mathrm{CPZ} \cdot{ }^{+}$from $\beta-\mathrm{CyD}$ takes place on the electrode surface during the electrolysis of the CPZ- $\beta$ CyD system.

On the basis of all the findings presented so far, the electrochemical oxidation mechanism of $\mathrm{CPZ}-\beta-\mathrm{CyD}$ system shown in Chart 3 is proposed.

first peak

$$
\begin{aligned}
& \mathrm{CPZ}+\mathrm{CyD} \rightleftharpoons \mathrm{CPZ}-\mathrm{CyD} \\
& \mathrm{CPZ}-\mathrm{CyD} \underset{+e}{\stackrel{-e}{\rightleftharpoons}} \mathrm{CPZ} \cdot++\mathrm{CyD} \\
& \mathrm{CPZ} \cdot++\mathrm{H}_{2} \mathrm{PO}_{4}^{-} \rightleftharpoons\left[\mathrm{CPZ}\left(\mathrm{HPO}_{4}\right)\right]^{-}+\mathrm{H}^{+} \\
& {\left[\mathrm{CPZ}\left(\mathrm{HPO}_{4}\right)\right] \cdot+\mathrm{CPZ} \cdot+\left[\mathrm{CPZ}\left(\mathrm{HPO}_{4}\right)\right]+\mathrm{CPZ}} \\
& {\left[\mathrm{CPZ}\left(\mathrm{HPO}_{4}\right)\right]+\mathrm{H}_{2} \mathrm{O} \longrightarrow \mathrm{CPZO}+\mathrm{H}_{2} \mathrm{PO}_{4}^{-}+\mathrm{H}^{+}}
\end{aligned}
$$

second peak

$$
\begin{aligned}
& \mathrm{CPZ} \cdot++\mathrm{H}_{2} \mathrm{PO}_{4}^{-} \rightleftharpoons\left[\mathrm{CPZ}\left(\mathrm{HPO}_{4}\right)\right] \cdot \cdot^{-}+\mathrm{H}^{+} \\
& {\left[\mathrm{CPZ}\left(\mathrm{HPO}_{4}\right)\right] \cdot \stackrel{-e}{\longrightarrow}\left[\mathrm{CPZ}\left(\mathrm{HPO}_{4}\right)\right]} \\
& {\left[\mathrm{CPZ}\left(\mathrm{HPO}_{4}\right)\right]+\mathrm{H}_{2} \mathrm{O} \longrightarrow-\mathrm{CPZO}+\mathrm{H}_{2} \mathrm{PO}_{4}^{-}+\mathrm{H}^{+}} \\
& \mathrm{CPZO}+\mathrm{CyD} \rightleftharpoons \mathrm{CPZO}-\mathrm{CyD}
\end{aligned}
$$

Chart 3

In this mechanism, $\beta$-CyD retards the first oxidation step of $\mathrm{CPZ}$, but the subsequent reactions take place through the same pathway as that proposed for the oxidation of CPZ without $\beta$-CyD. ${ }^{15)}$ Thus it seems most likely that $\mathrm{CyD}$ serves as a stabilizer of $\mathrm{CPZ}$ by 
preventing its photodecomposition, since $\beta$-CyD provides good protection against the oxidation of $\mathrm{CPZ}$. The cation radical $\mathrm{CPZ} \cdot{ }^{+}$is an active pharmacological entity in vivo. The fact that the electrochemical oxidation potential of $\mathrm{CPZ} \cdot{ }^{+}$remains unchanged even when $\beta$ $\mathrm{CyD}$ is present in the solution probably indicates that the pharmacological activity of CPZ is not affected by $\beta-\mathrm{CyD}$ at the receptor site of $\mathrm{CPZ}$. Therefore, CyD holds promise as a carrier of CPZ.

\section{References}

1) K. Uekama, T. Irie, M. Sunada, M. Otagiri and K. Tsubaki, J. Pharm. Dyn., 4, 142 (1981).

2) S. Egawa, Yakuzaigaku, 21, 183 (1961).

3) M. Otagiri, K. Uekama, T. Irie, M. Sunada, T. Miyata and Y. Kasé, "Proceedings of the First International Symposium on Cyclodextrins," Akadémiai Kiadó, Budapest, 1982, p. 389.

4) M. L. Bender and M. Komiyama, "Cyclodextrin Chemistry," Springer-Verlag, Berlin, 1978.

5) F. H. Merkle and C. A. Discher, J. Pharm. Sci., 53, 620 (1964).

6) R. L. McCreery, J. Pharm. Sci., 66, 367 (1977).

7) T. Akera and T. Brody, Mol. Pharmacol., 4, 600 (1968).

8) L. H. Piette, G. Bulow and I. Yamazaki, Biochim. Biophys. Acta, 88, 120 (1964).

9) I. S. Forrest and D. E. Green, J. Forensic Sci., 17, 592 (1972).

10) T. Akera and T. Brody, Biochem. Pharmacol., 21, 1403 (1972).

11) S. Ohnishi and H. McConnel, J. Am. Chem. Soc., 87, 2293 (1965).

12) G. M. Gooly, H. Keyser and F. Setchell, Nature (London), 223, 80 (1969).

13) P. H. Sackett and R. L. McCreery, J. Med. Chem., 22, 1447 (1979).

14) H. Y. Cheng, P. H. Sackett and R. L. McCreery, J. Am. Chem. Soc., 100, 962 (1978).

15) K. Takamura, S. Inoue, F. Kusu, M. Otagiri and K. Uekama, Chem. Pharm. Bull., 31, 1821 (1983).

16) M. Otagiri, K. Uekama and K. Ikeda, Chem. Pharm. Bull., 23, 188 (1975).

17) M. Otagiri, J. H. Perrin, K. Uekama, K. Ikeda and K. Takeo, Pharm. Acta Helv., 51, 343 (1976).

18) R. S. Nicholson and I. Shain, Anal. Chem., 36, 706 (1964).

19) M. Nakagaki and S. Okada, Yakugaku Zasshi, 97, 495 (1977). 